\title{
University of Illinois Temperature Sensors
}

\author{
K. L. Davis \\ D. L. Knudson \\ J. L. Rempe \\ B. M. Chase
}

September 18, 2014

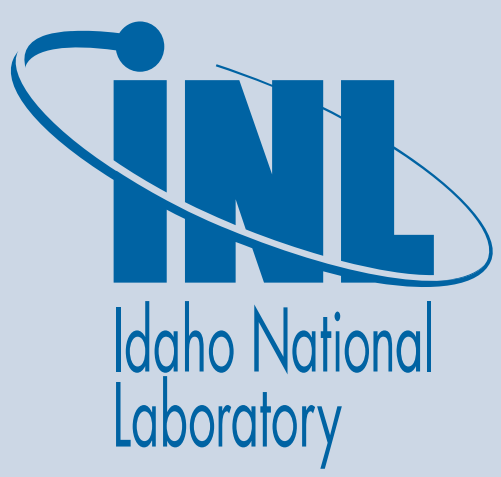




\section{DISCLAIMER}

This information was prepared as an account of work sponsored by an agency of the U.S. Government. Neither the U.S. Government nor any agency thereof, nor any of their employees, makes any warranty, express or implied, or assumes any legal liability or responsibility for the accuracy, completeness, or usefulness of any information, apparatus, product, or process disclosed, or represents that its use would not infringe privately owned rights. References herein to any specific commercial product, process, or service by trade name, trademark, manufacturer, or otherwise, does not necessarily constitute or imply its endorsement, recommendation, or favoring by the U.S. Government or any agency thereof. The views and opinions of authors expressed herein do not necessarily state or reflect those of the U.S. Government or any agency thereof. 
INL/EXT-14-33136

\title{
University of Illinois Temperature Sensors
}

\author{
K. L. Davis \\ D. L. Knudson \\ J. L. Rempe \\ B. M. Chase
}

September 18, 2014

\author{
Idaho National Laboratory \\ Idaho Falls, Idaho 83415 \\ Prepared for the \\ U.S. Department of Energy \\ Office of Nuclear Energy, Science, and Technology \\ Under DOE Idaho Operations Office \\ Contract DE-AC07-05ID14517
}





\section{University of Illinois Temperature Sensors}

\section{Introduction}

This document summarizes background information and presents results related to temperature measurements in the Advanced Test Reactor (ATR) National Scientific User Facility (NSUF) University of Illinois Project 29609 irradiation. As documented in Reference 1, the objective of this test was to assess the radiation performance of ferritic alloys for advanced reactor applications. The FeCr-based alloy system is considered the lead alloy system for a variety of advanced reactor components and applications. Irradiations of FeCr alloy samples were performed using the Hydraulic Shuttle Irradiation System (HSIS) in the B-7 position and in a static capsule in the A-11 position of the ATR.

Only the HSIS capsules contained temperature sensors, consisting of quartz-encapsulated melt wire assemblies and Silicon Carbide (SiC) temperature monitors. A total of six HSIS titanium capsules were included in the test, and the capsules were irradiated for up to 10 Effective Full Power Days (EFPD) to a maximum fluence of $7 \times 10^{19} \mathrm{n} / \mathrm{cm}^{2}(\mathrm{E}>1 \mathrm{MeV})$. Pre-test thermal and reactor physics analyses ${ }^{2,3}$ indicate that two capsules (UI-0.01-300 and UI-0.1-300) would be irradiated at $300{ }^{\circ} \mathrm{C}$ (with the $\mathrm{SiC}$ monitors receiving a 0.01 and 0.1 dpa dose, respectively); two capsules (UI-0.01-450 and UI-0.1-450) would be irradiated at $450{ }^{\circ} \mathrm{C}$ (with the $\mathrm{SiC}$ monitors receiving a 0.01 and $0.1 \mathrm{dpa}$ dose, respectively); and two capsules (UI-0.01-550 and UI-0.1-550) would be irradiated at $550{ }^{\circ} \mathrm{C}$ (with the $\mathrm{SiC}$ monitors receiving a 0.01 and 0.1 dpa dose, respectively). Figure 1 shows the design of the HSIS capsule with the location of a SiC temperature monitor and the location of a quartz-encapsulated melt wire assembly (containing four melt wires). Figure 2 shows a photo of one of the capsules taken prior to irradiation ( $\mathrm{FeCr}$ alloy samples included tensile specimens and Transmission Electron Microscopy (TEM) samples), and Figure 3 shows a radiograph of one of the capsules prior to irradiation.

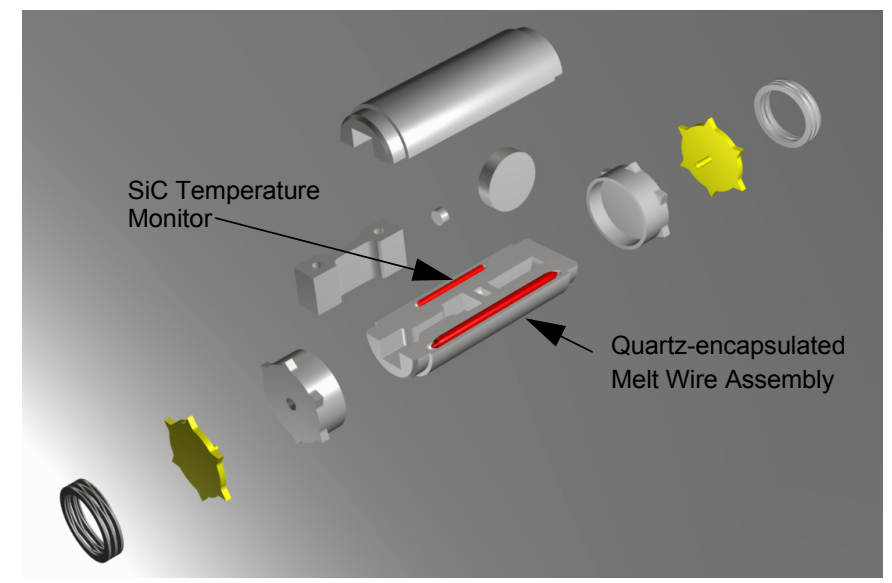

Figure 1. University of Illinois HSIS capsule design.

This report documents results from an evaluation of the temperature sensors for three of the six HSIS capsules including UI-0.01-300 (identified as KGT-1174), UI-0.01-450 (identified as KGT-1208), and UI-0.1-450 (identified as KGT-1139). It is critical to note that the predicted dose for all of these capsules is below the recommended range for $\mathrm{SiC}$ temperature monitor use (see Section 3). Consequently, uncertainties in this evaluation cannot be readily quantified. 


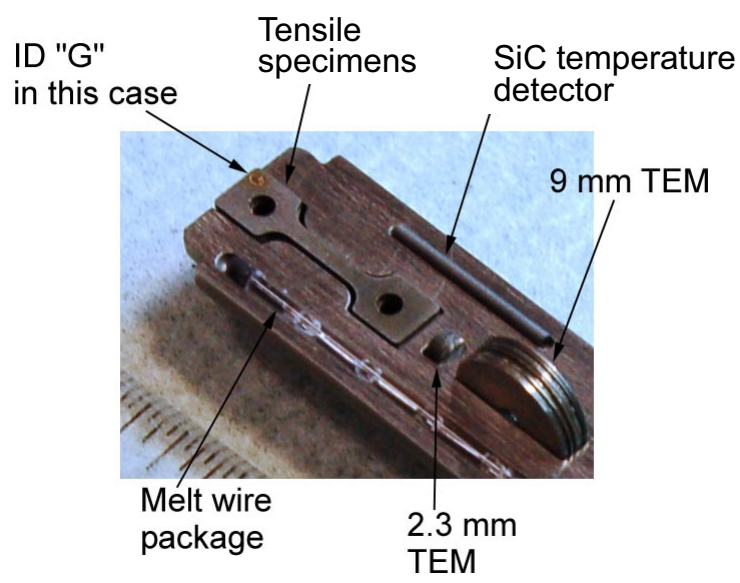

Figure 2. Photo of typical University of Illinois capsule prior to irradiation.

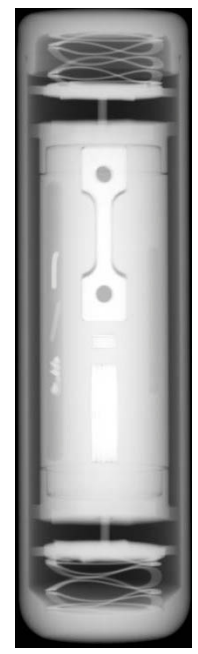

Figure 3. Radiograph of typical University of Illinois capsule prior to irradiation.

\section{Melt Wires}

An evaluation of the melt wire assemblies was undertaken to validate temperature predictions from the pretest thermal and reactor physics analyses. Insights about peak irradiation temperature gained from melt wire evaluations were used to select appropriate temperatures for efficient $\mathrm{SiC}$ temperature monitor evaluations.

\subsection{Selection and Prior Experience with Selected Wires}

The melt wires listed in Table 1 were selected to bound estimated temperatures for the University of Illinois test. These materials were selected from a library of melt wire materials maintained by Idaho National Laboratory's (INL's) High Temperature Test Laboratory (HTTL). ${ }^{4,5}$ Many of the wires included in this test had their melting temperature evaluated using an HTTL differential scanning calorimeter (DSC). ${ }^{6,7}$ In addition, HTTL furnace tests of quartz encapsulated tubes containing materials from the HTTL melt wire library provide insights related to the ability to visually discern melting after heating to temperatures above melting. ${ }^{6,7}$ These insights are summarized in column 3 of Table 1. 
Table 1. Summary of melt wires included in University of Illinois test.

\begin{tabular}{|c|c|c|}
\hline $\begin{array}{l}\text { Melt Wire } \\
\text { Material }^{\mathbf{a}}\end{array}$ & $\begin{array}{c}\text { Melt } \\
\text { Temperature } \\
\left({ }^{\circ} \mathrm{C}\right)\end{array}$ & Comment \\
\hline \multicolumn{3}{|r|}{$300^{\circ} \mathrm{C}$ Capsules } \\
\hline $90 \mathrm{~Pb} 10 \mathrm{Sb}$ & 252.4 & HTTL Evaluated (TEV-1007). \\
\hline $80 \mathrm{Au} 20 \mathrm{Sn}$ & 279.5 & HTTL Evaluated (TEV-1007). \\
\hline $90 \mathrm{~Pb} 5 \mathrm{Ag} 5 \mathrm{Sn}$ & 302.9 & HTTL Evaluated (TEV-1007). \\
\hline $100 \mathrm{~Pb}$ & 327.5 & $\begin{array}{l}\text { Furnace tests indicate melting from } 335 \text { to } 386^{\circ} \mathrm{C} \text {; oxidation may have caused } \\
\text { discrepancy. }\end{array}$ \\
\hline \multicolumn{3}{|r|}{$450^{\circ} \mathrm{C}$ Capsules } \\
\hline $100 \mathrm{~Pb}$ & 327.5 & $\begin{array}{l}\text { Furnace tests indicate melting ranged from } 335 \text { to } 386^{\circ} \mathrm{C} \text {; oxidation may have } \\
\text { caused discrepancy. }\end{array}$ \\
\hline $100 \mathrm{Zn}$ & 419.3 & $\begin{array}{l}\text { HTTL evaluated (TEV-1141); furnace tests difficult to interpret (some } \\
\text { discoloration occurs in some tests after } 335^{\circ} \mathrm{C} \text {; slight surface changes at } 430^{\circ} \mathrm{C} \\
\text { may indicate melt). }\end{array}$ \\
\hline $80 \mathrm{Sb} 20 \mathrm{Zn}$ & 507.8 & $\begin{array}{l}\text { HTTL evaluated (TEV-1175); chards; furnace tests indicate melting not until } \\
520 \text { to } 540^{\circ} \mathrm{C} \text {; oxidation may have caused discrepancy. }\end{array}$ \\
\hline $100 \mathrm{Al}$ & 660.5 & $\begin{array}{l}\text { Furnace test results varied; some results indicate discoloration and morphology } \\
\text { observed by } 670^{\circ} \mathrm{C} \text { and melting by } 710^{\circ} \mathrm{C} \text {. }\end{array}$ \\
\hline
\end{tabular}

a. Listed with weight percent of each element.

\subsection{Initial Melt Wire Results}

Post irradiation evaluations indicate that none of the quartz tubes experienced any darkening. The endstate of wires was easily observed, but not easily photographed. Preliminary results are summarized in this section with recommendations for conducting $\mathrm{SiC}$ temperature monitor evaluations.

\subsection{1. $300{ }^{\circ} \mathrm{C}$ Results}

Post-irradiation photos of KGT-1174 (capsule UI-0.01-300), shown in Figure 4, indicate that all wire materials melted, which implies the peak irradiation temperature exceeded $328^{\circ} \mathrm{C}$.
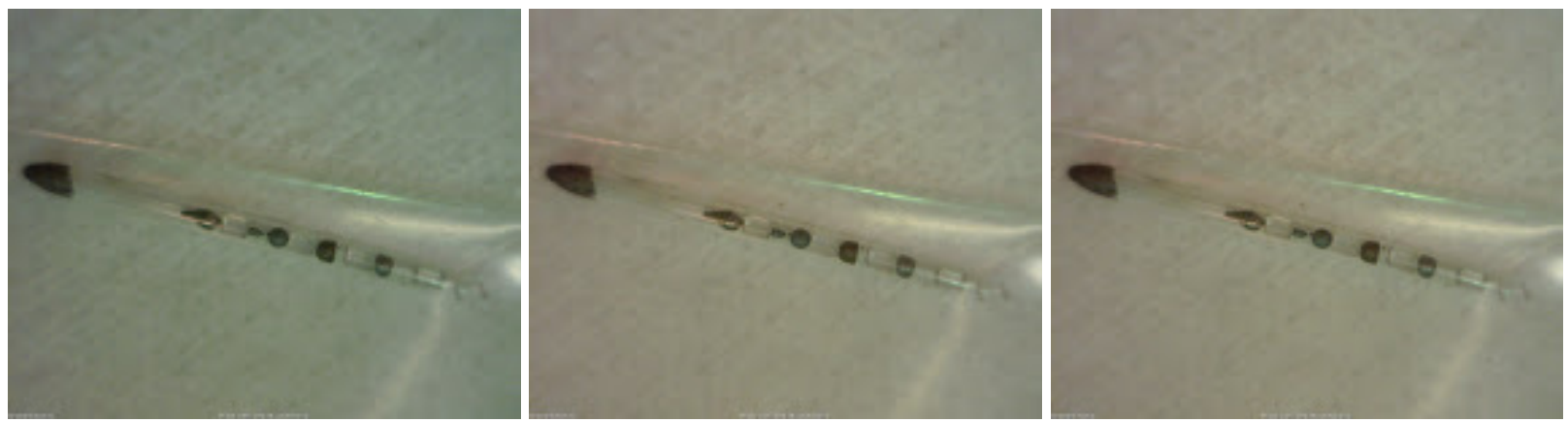

Figure 4. KGT-1174 (capsule UI-0.01-300) with higher melting point material, 100Pb, near painted end.

\subsection{2. $450{ }^{\circ} \mathrm{C}$ Results}

Post-irradiation photos for the two $450{ }^{\circ} \mathrm{C}$ capsules (KGT-1208 [capsule UI-0.01-450] and KGT-1139 [capsule UI-0.1-450]), shown in Figures 5 and 6, are less clear. The photos suggest only that the lowest 
melting point material $(100 \mathrm{~Pb})$ may have melted, which implies peak irradiation temperatures may not have exceeded $419{ }^{\circ} \mathrm{C}$. However, the melt wire evaluation for these capsules is inconclusive because the photos lack sufficient quality/resolution.
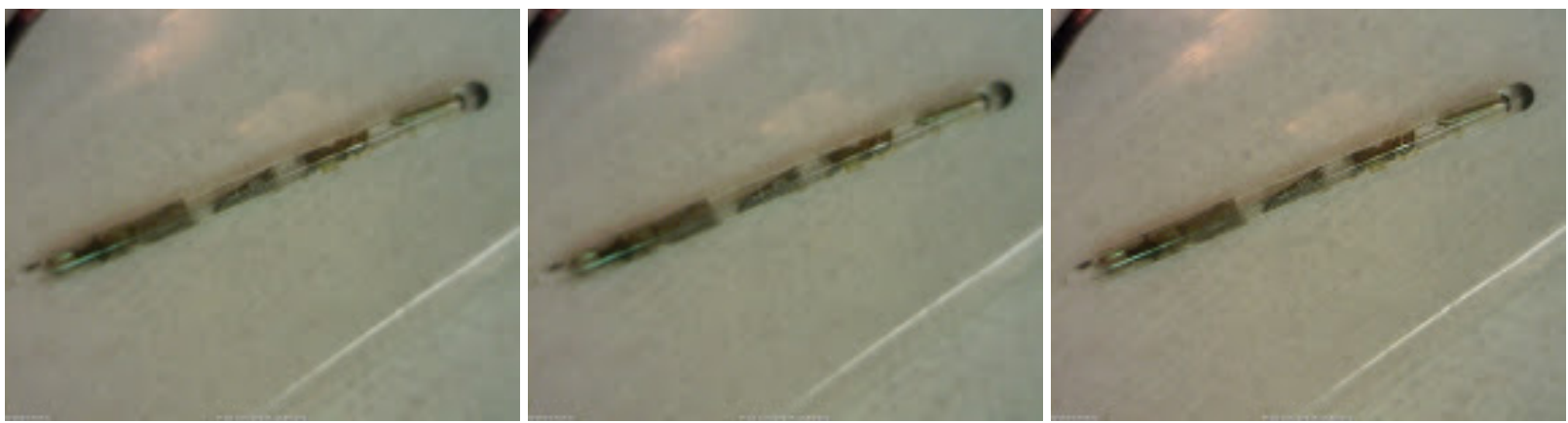

Figure 5. KGT-1208 (capsule UI-0.01-450) with higher melting point material, 100Al, near painted end.
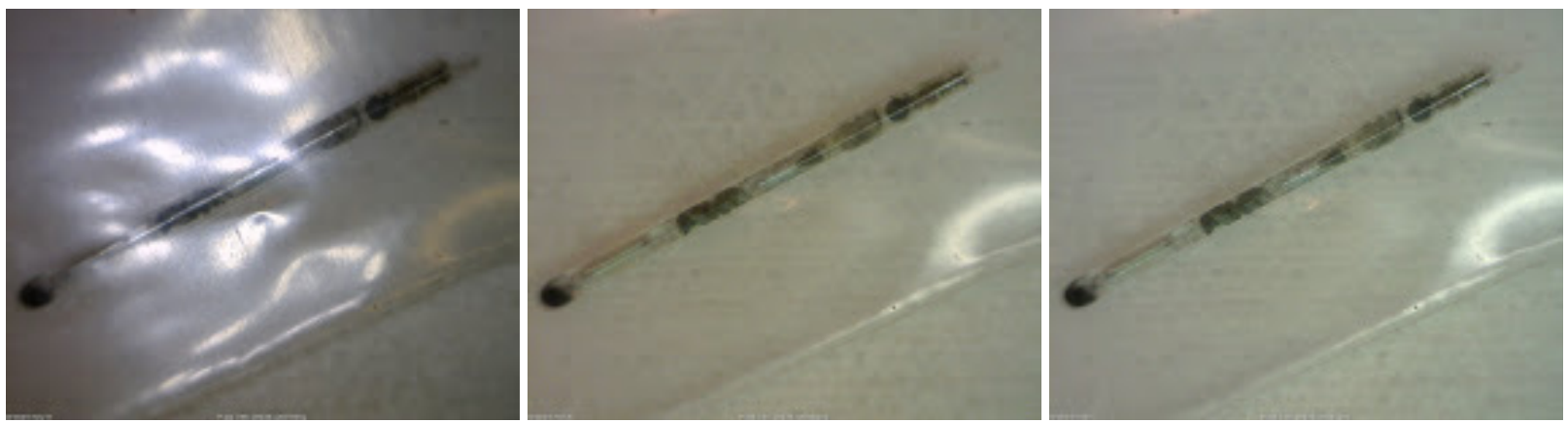

Figure 6. KGT-1139 (capsule UI-0.1-450) with higher melting point material, 100Al, near painted end.

\subsubsection{Preliminary Conclusions and Recommendations for SiC Evaluations}

Table 2 summarizes recommendations for $\mathrm{SiC}$ monitor evaluations based on available melt wire evaluation and pre-test thermal analysis results.

Table 2. Preliminary melt wire evaluation for the University of Illinois test.

\begin{tabular}{|c|c|}
\hline Capsule & Comment and Recommendation \\
\hline & $300^{\circ} \mathrm{C}$ Capsules \\
\hline \multirow[t]{2}{*}{ KGT-1174 } & All materials melted. Temperatures exceeded $328^{\circ} \mathrm{C}$. \\
\hline & $\begin{array}{l}\text { Recommendation for } \mathrm{SiC} \text { Monitor Evaluations: Start at } 40{ }^{\circ} \mathrm{C} \text {, increment to anneal } \\
\text { temperatures of } 50,100,150 \text {, and } 250^{\circ} \mathrm{C} \text {, then increase the anneal temperature for } \\
\text { subsequent data points by } 10^{\circ} \mathrm{C} \text { until a change in resistivity is observed. }\end{array}$ \\
\hline \multicolumn{2}{|r|}{$450{ }^{\circ} \mathrm{C}$ Capsules } \\
\hline \multirow{2}{*}{$\begin{array}{l}\text { KGT-1208 } \\
\quad \text { and } \\
\text { KGT-1139 }\end{array}$} & Temperatures may have exceeded $328^{\circ} \mathrm{C}$ but less than $419^{\circ} \mathrm{C}$. \\
\hline & $\begin{array}{l}\text { Recommendation for } \mathrm{SiC} \text { Monitor Evaluations: Start at } 40^{\circ} \mathrm{C} \text {, increment to anneal } \\
\text { temperatures of } 50,100,150,200,250,300,350 \text {, and } 400^{\circ} \mathrm{C} \text {, then increase the anneal } \\
\text { temperature for subsequent data points by } 10^{\circ} \mathrm{C} \text { until a change in resistivity is observed. }\end{array}$ \\
\hline
\end{tabular}




\section{SiC Evaluations}

As discussed in Section 1, SiC temperature monitors were incorporated into University of Illinois test capsules as illustrated in Figures 1 through 3. (Note that these monitors were a fully dense chemical vapor deposition of silicon carbide procured from Dow Chemical Company. ${ }^{a}$ ) Results from thermal analyses of the SiC monitors designated KGT-1174, KGT-1208, and KGT-1139 are reported in Table 3.

Table 3. Estimated temperatures for $\mathrm{SiC}$ monitors.

\begin{tabular}{|c|c|}
\hline Monitor Identification & Thermal Analysis Predictions $\left({ }^{\circ} \mathbf{C}\right)$ \\
\hline KGT-1174 (capsule UI-0.01-300) & 300 \\
\hline KGT-1208 (capsule UI-0.01-450) & 450 \\
\hline KGT-1139 (capsule UI-0.1-450) & 450 \\
\hline
\end{tabular}

\subsection{Background}

$\mathrm{SiC}$ has been used as a post-irradiation monitor to infer peak irradiation temperature since the early 1960s. As noted in Reference 8, several researchers have observed that neutron irradiation induced lattice expansion of $\mathrm{SiC}$ anneals out when the post-irradiation annealing temperature exceeds the irradiation temperature. More recent evaluations ${ }^{8-10}$ infer peak irradiation temperatures using changes in electrical resistivity because of improved accuracy, ease of measurement, and reduced costs of the experimental setup. Comparisons of temperatures inferred from $\mathrm{SiC}$ measurements and thermocouple data indicate that accuracies of approximately $20^{\circ} \mathrm{C}$ are possible for dose ranges of 1 to $8 \mathrm{dpa}$ and temperatures from 200 to at least $800^{\circ} \mathrm{C}$.

There are several limitations associated with the use of $\mathrm{SiC}$ temperature detectors. The use of $\mathrm{SiC}$ as a temperature monitor is intended for constant temperature irradiations. Reference 9 cites several specific examples where temperature variations during irradiation can introduce uncertainty in the $\mathrm{SiC}$ monitor measurements including:

- Irradiation temperatures rising during the latter part of irradiation. SiC swelling saturates at low fluence. For damages greater than $0.1 \mathrm{dpa}$, the increasing temperature will anneal out defects that occur at the lower irradiation temperature, while creating stable defects at the higher temperature. When isochronal annealing is performed, lower temperature defects are removed; and the recovery curve will be smeared to somewhat higher temperatures. If the temperature increase during irradiation is not great, or the time at higher temperature not too long, then the original departure from linearity will still give the earlier irradiation temperature.

- Irradiation temperatures decreasing during irradiation. This decrease will lead to defects being created and frozen-in at the higher-temperature, while continuing to create lower temperature defects. The isochronal anneal will then give an indication of the lowest irradiation temperature (in this case at the end of the irradiation period), and the recovery curve will be smeared because it will continue to anneal higher and higher temperature stable defects.

- Upward or downward temperature spikes during irradiation. Depending on the time at temperature, the effect will be to smear the recovery curve.

However, if irradiation tests are conducted at or near the same temperature when the reactor is at power, none of these situations are of concern.

a. Purchased under Idaho National Laboratory quality assurance identifier QA 165156. 
In addition, there are other sources of uncertainty that one should consider when comparing results from $\mathrm{SiC}$ temperature monitors and analysis predictions for peak temperatures. For example, Reference 8 provides information regarding the influence manufacturing tolerances of gas gaps can have on temperature control in irradiation tests. Thermal analysis of prior tests have been shown to have errors of up to $100{ }^{\circ} \mathrm{C}$ in tests conducted at $1400{ }^{\circ} \mathrm{C}$.

\subsection{Experimental Setup}

Electrical resistivity measurements were used to infer the peak irradiation temperature of the University of Illinois SiC monitors. Figure 7 depicts the equipment at the HTTL used to evaluate SiC monitors. The SiC monitors were heated isochronally in the annealing furnace. Based on the experiment analysis, the annealing temperatures were selected as specified in Section 2.2.3. The annealing furnace is located under a ventilation hood within a stainless steel enclosure. Annealing temperatures are recorded using a National Institute Standards and Technology (NIST) traceable, calibrated thermocouple inserted into an alumina tube in the furnace. After each isochronal annealing, the specimens are placed in a specialized fixture designed to take resistance measurements and inserted into a constant temperature chamber, maintained at $40^{\circ} \mathrm{C}$, for a minimum of 30 minutes. After the sensor has equilibrated with the temperature in the chamber for at least 30 minutes, the resistance is measured using a specialized fixture which is connected to the calibrated DC power analyzer.

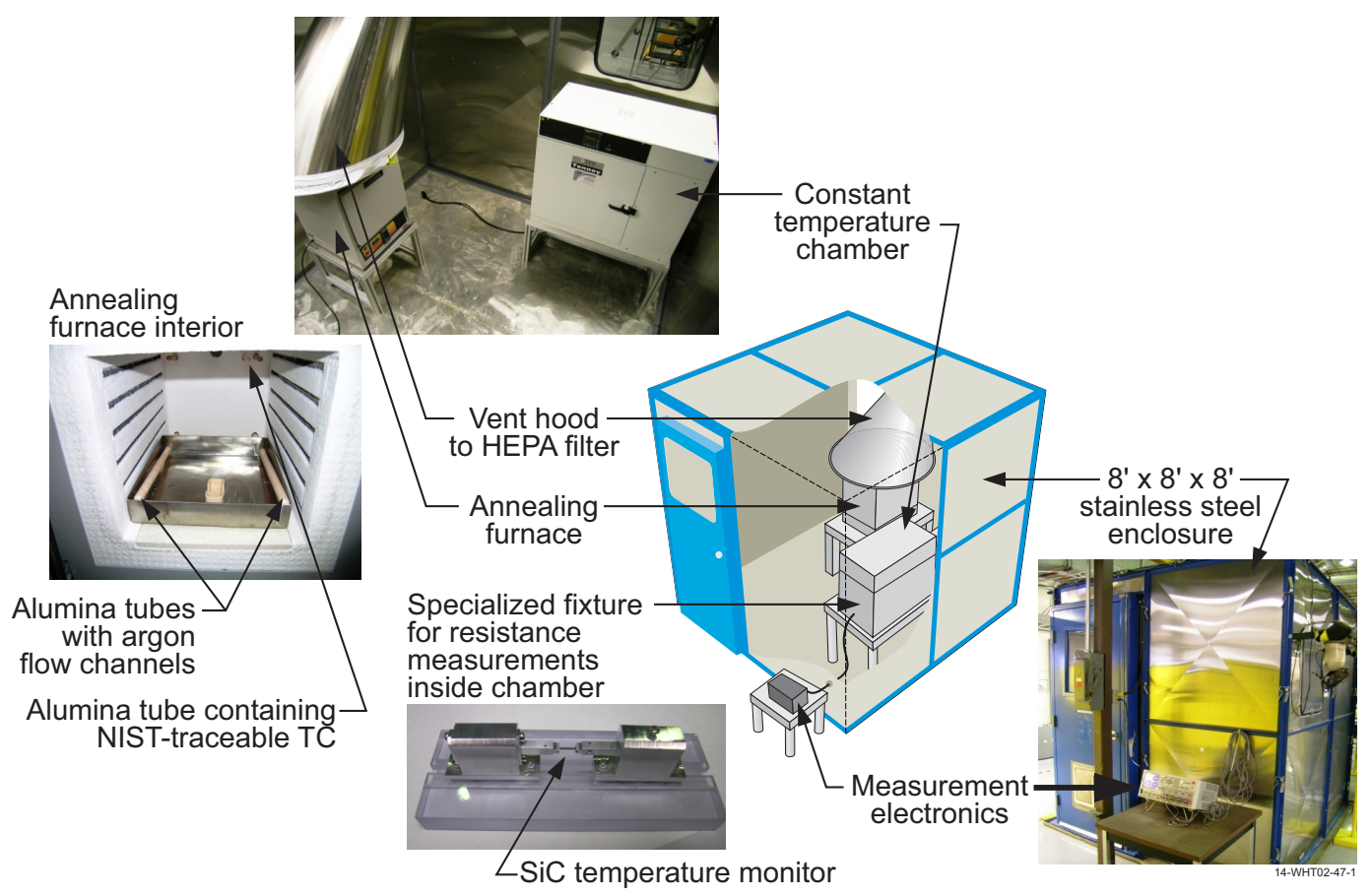

Figure 7. SiC equipment setup.

Initial resistance measurements of the $\mathrm{SiC}$ monitors are performed to determine the power analyzer settings to use for each post-anneal measurement. For the given voltage, the ohmic response is used to ensure resistance heating in the sample is minimized and the current signal is stable. Figures 8 through 11 contain the plots of the ohmic response for the KGT-1174, KGT-1208, KGT-1139, and reference monitors, respectively. Evaluation of the data showed that a small amount of resistance heating was occurring at voltage settings above $8 \mathrm{~V}$, while voltage settings between 2 and $8 \mathrm{~V}$ produced stable current output. For these tests, an applied voltage of $4 \mathrm{~V}$ or $8 \mathrm{~V}$ was selected to provide the desired current. 


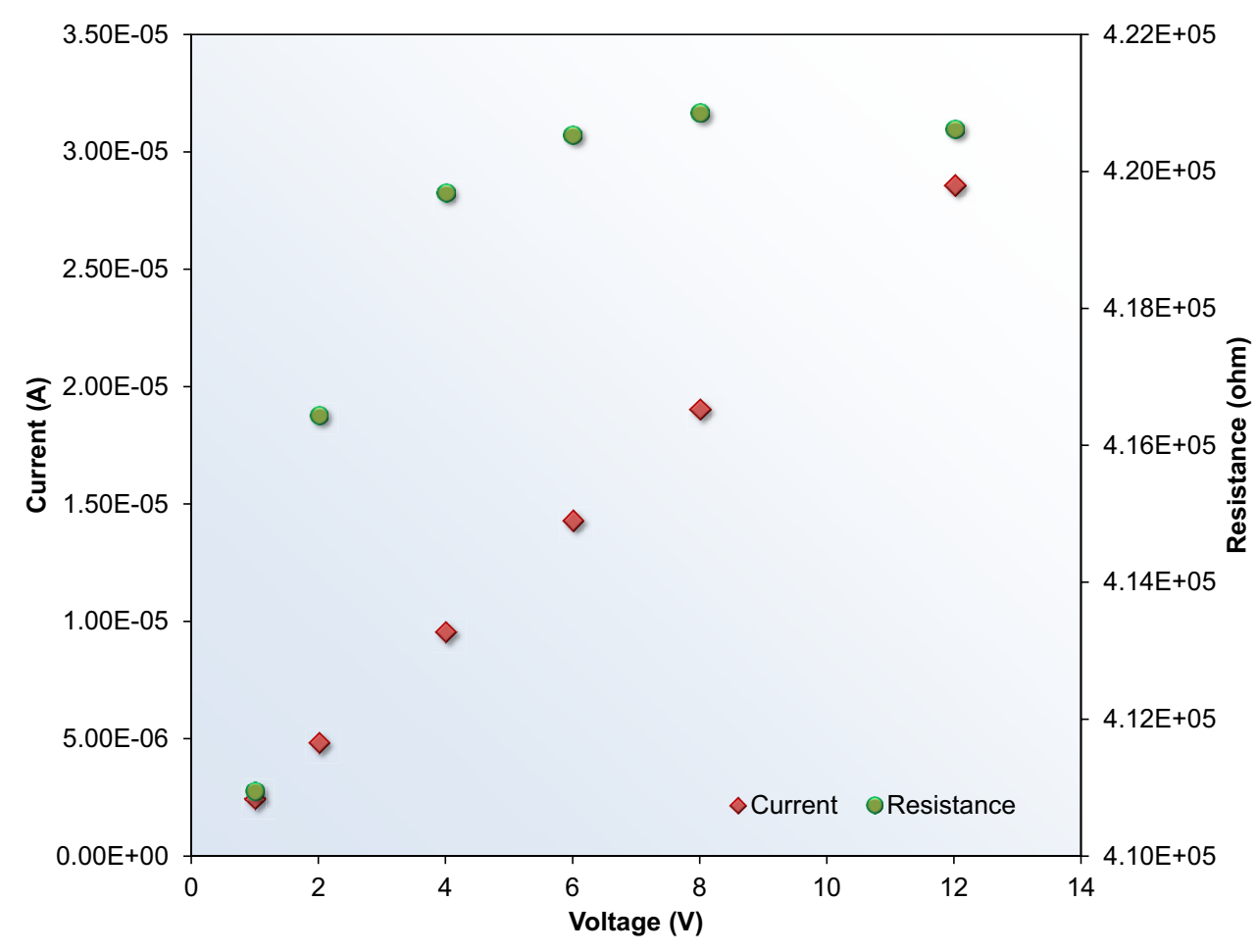

Figure 8. KGT-1174 ohmic response.

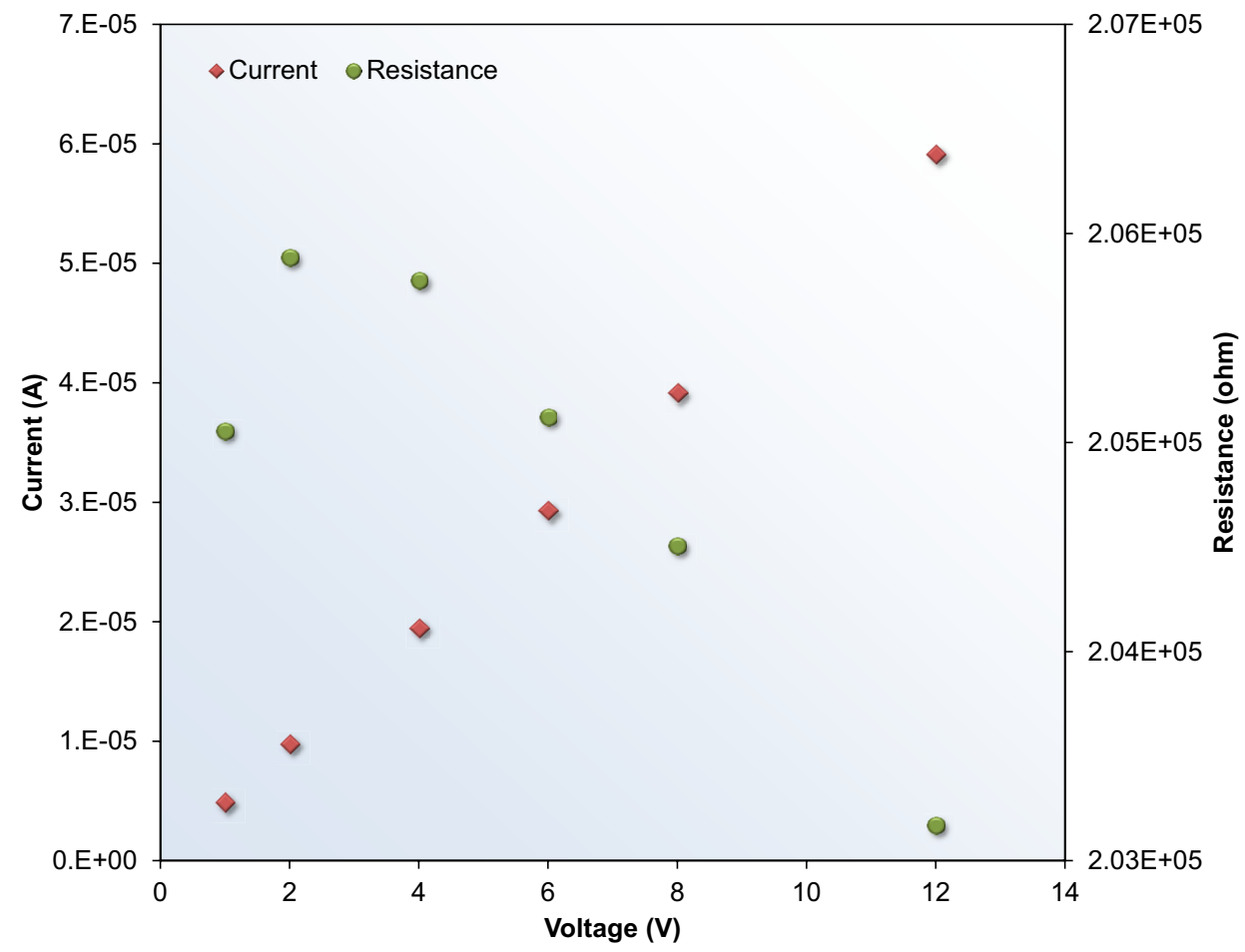

Figure 9. KGT-1208 ohmic response. 


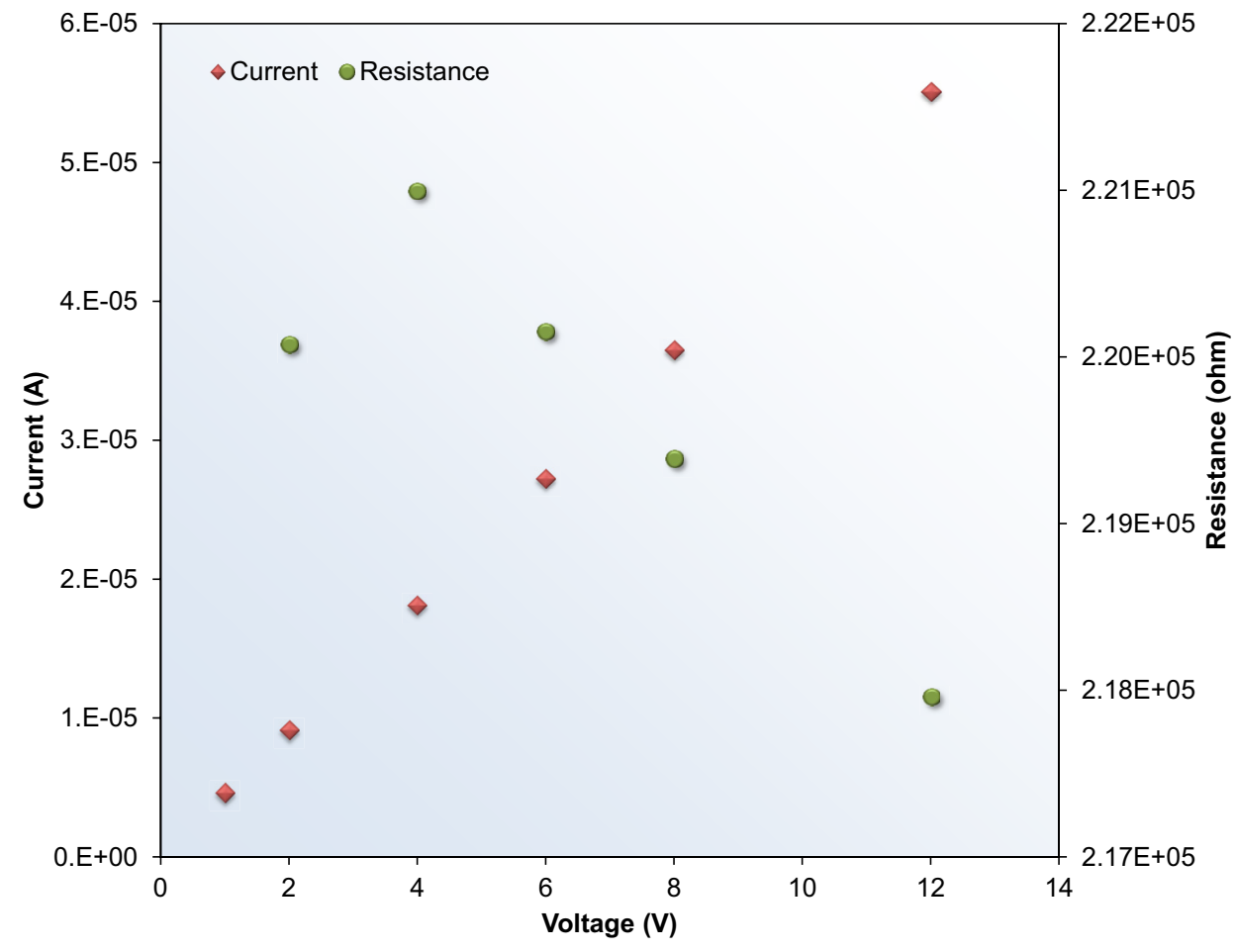

Figure 10. KGT-1139 ohmic response.

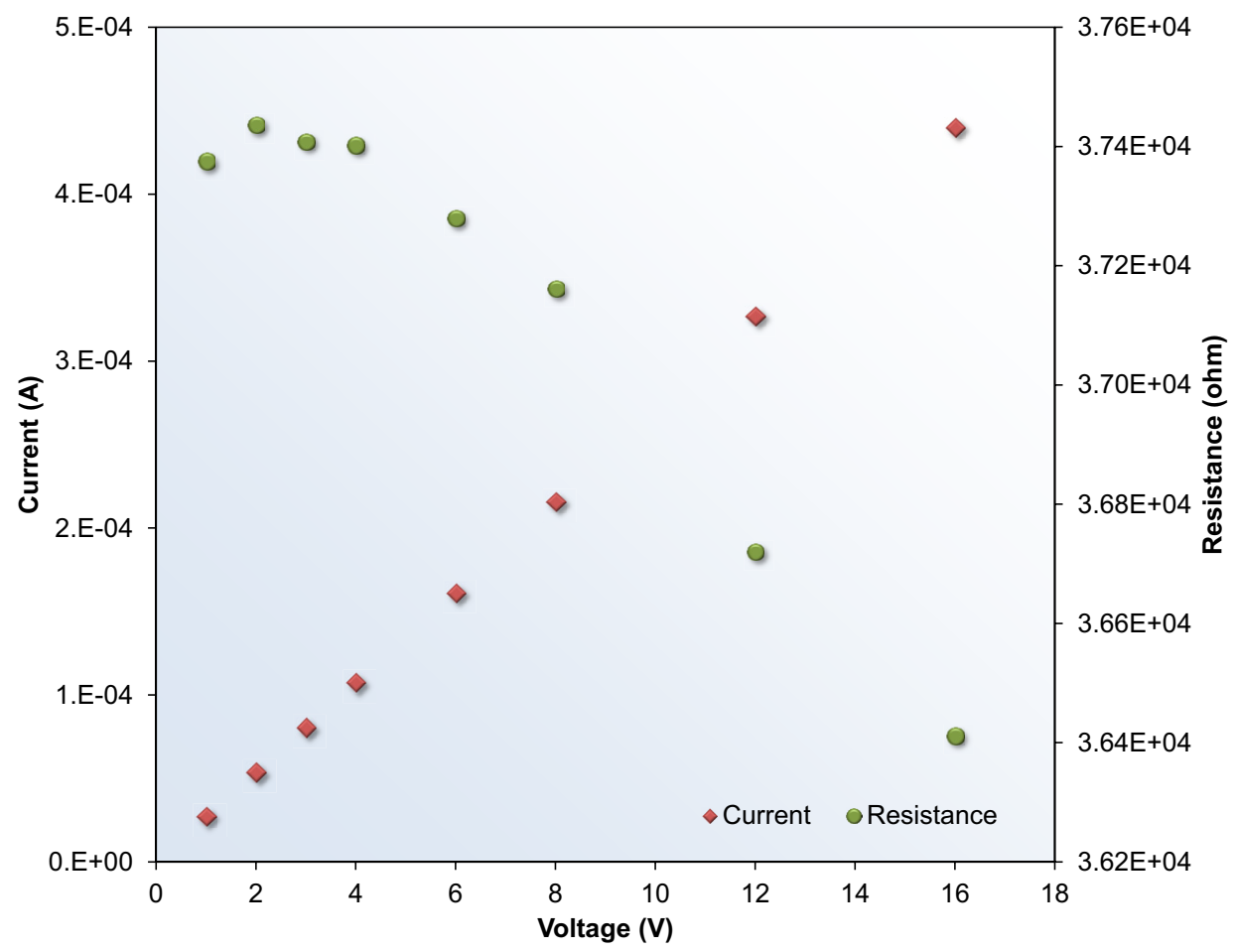

Figure 11. Reference monitor ohmic response. 
Evaluations above $400{ }^{\circ} \mathrm{C}$ require a reference monitor to ensure oxidation is not affecting the measurements. The reference monitor is an un-irradiated monitor that is annealed with the test monitors. Measurements of the reference monitor are taken after each anneal along with the test monitor. The resistivity of the reference monitor should stay the same throughout the evaluation. If the reference monitor resistivity deviates statistically from the average, it could be an indication that oxidation is developing on the SiC monitors.

\subsection{Results}

In comparing information in Sections 1 and 3.1, it may be observed that dose ranges for the SiC monitors included in the University of Illinois tests were well below accepted ranges for their use (e.g., 1 to 8 dpa). Nevertheless, evaluations were performed to gain insights about their use in lower dose ranges.

\subsubsection{KGT-1174 Monitor}

The planned dose for KGT-1174 was $0.01 \mathrm{dpa}$, which is well below the recommended range of 1 to $8 \mathrm{dpa}$. Also, radiation surveys performed on KGT-1174 showed no activity above background. Radiological measurements of other University of Illinois $\mathrm{SiC}$ monitors ranged from 25,000 to 75,000 dpm, indicating that KGT-1174 may not have been irradiated to the planned dose of 0.01 dpa. Figure 12 is a plot of the resistivity data for the KGT-1174 monitor. Although the predicted peak irradiation temperature was $300{ }^{\circ} \mathrm{C}$ (see Table 3), the peak irradiation temperature based on the resistivity data was indeterminate, as no increase in resistivity was measured for the evaluated annealing temperatures. (Normally, the evaluation would have continued to see if an upward trend could be established. However, because of the very low dose and associated uncertainty, this evaluation was truncated at a final annealing temperature of $400{ }^{\circ} \mathrm{C}$.)

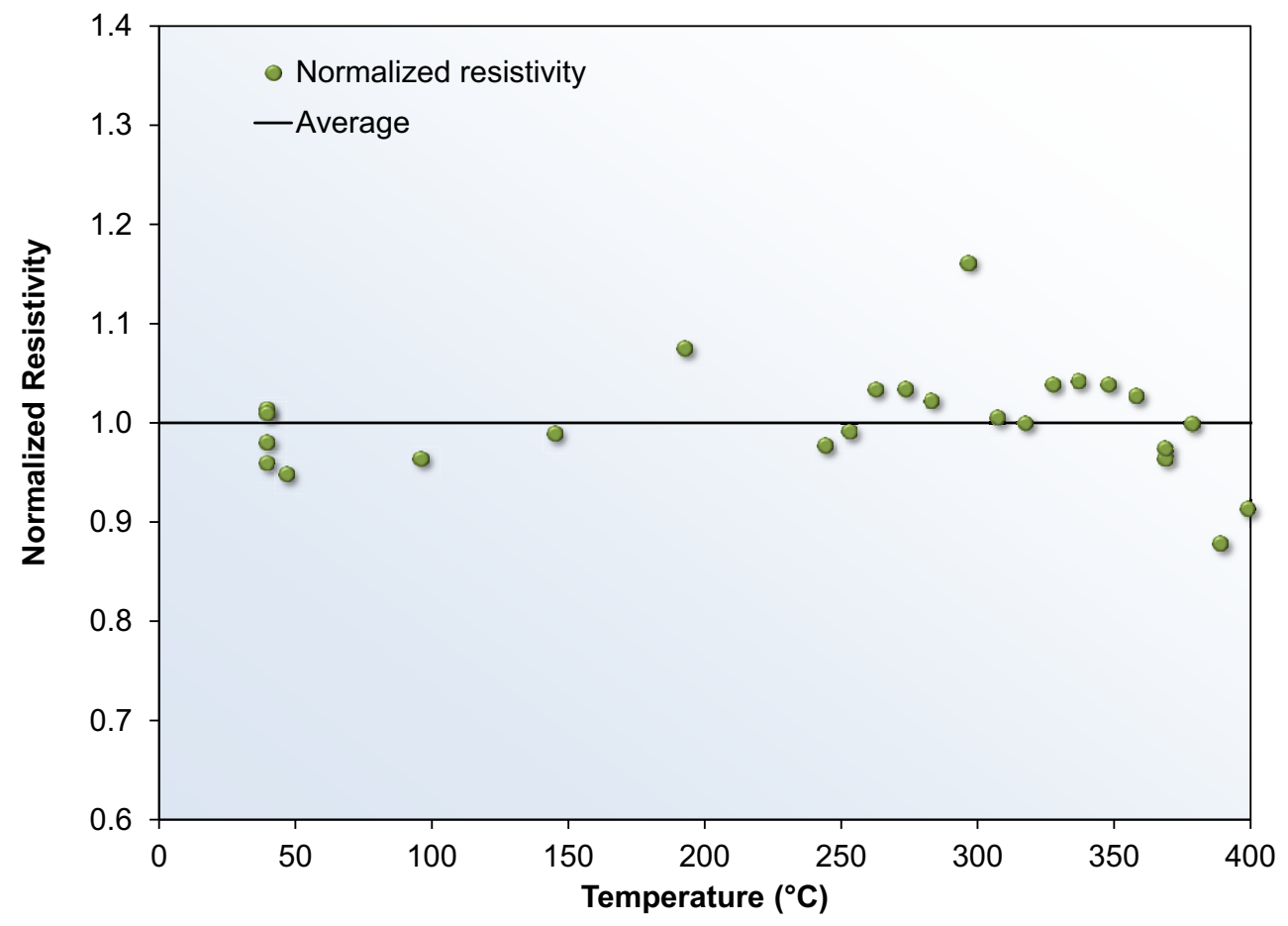

Figure 12. Resistivity data for KGT-1174 monitor. 


\subsubsection{KGT-1208 Monitor}

The planned dose for KGT-1208 was $0.01 \mathrm{dpa}$, which is also well below the recommended range of 1 to 8 dpa. Figure 13 is a plot of the resistivity data for the KGT-1174 monitor. Although the predicted peak irradiation temperature was $450{ }^{\circ} \mathrm{C}$ (see Table 3), the peak irradiation temperature based on the resistivity data was indeterminate, as no increase in resistivity was measured for the evaluated annealing temperatures. (Normally, the evaluation would have continued to see if an upward trend could be established. However, because of the very low dose and associated uncertainty, this evaluation was truncated at a final annealing temperature of $470{ }^{\circ} \mathrm{C}$.)

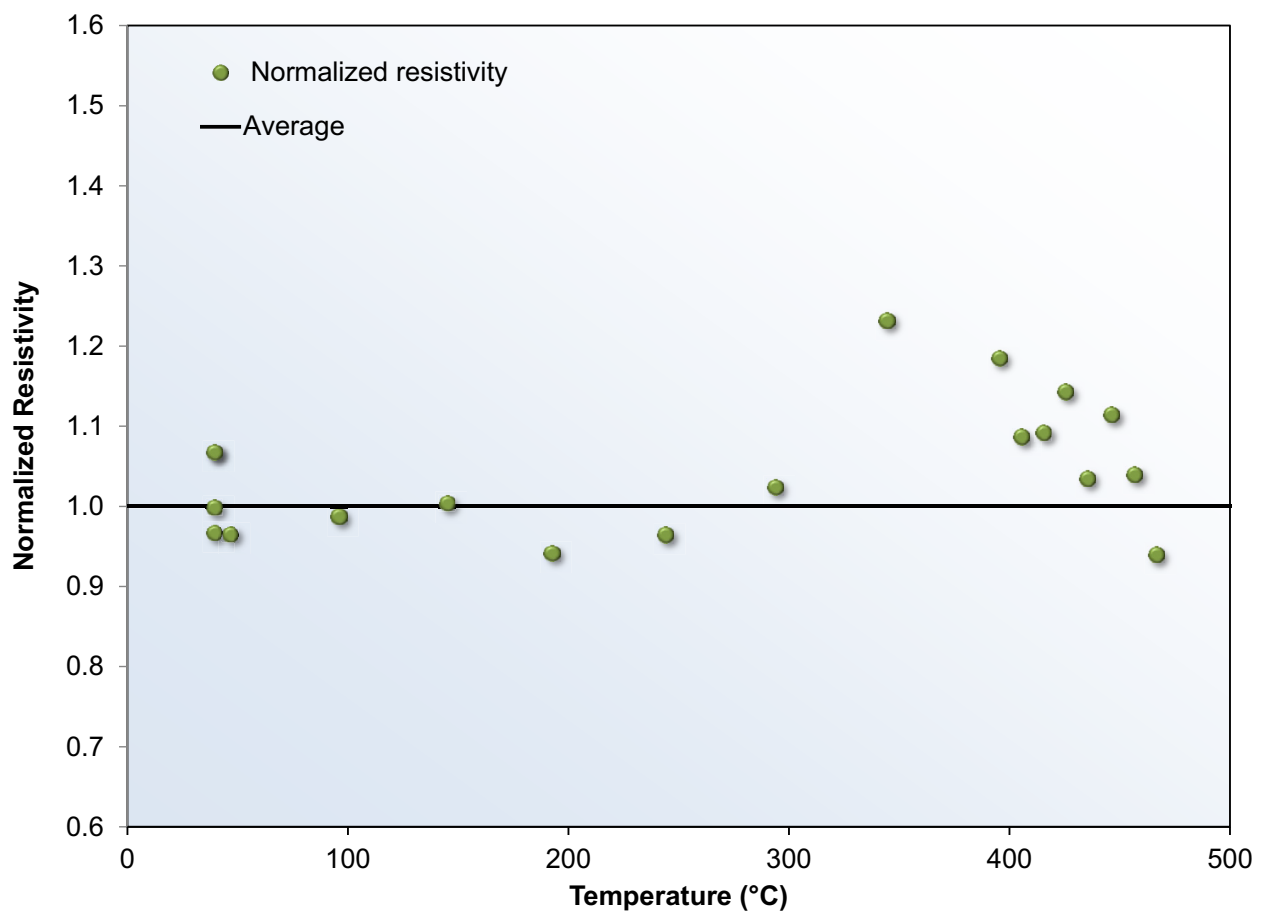

Figure 13. Resistivity data for KGT-1208 monitor.

\subsubsection{KGT-1139 Monitor}

As previously noted, the KGT-1139 monitor only received a dose of $0.1 \mathrm{dpa}$, which is well below the recommended range of 1 to $8 \mathrm{dpa}$. Figure 14 is a plot of the resistivity data for the KGT-1139 monitor. Although the predicted peak irradiation temperature was $450{ }^{\circ} \mathrm{C}$ (see Table 3), the peak irradiation temperature based on the resistivity data was indeterminate, as no increase in resistivity was measured for the evaluated annealing temperatures. (Normally, the evaluation would have continued to see if an upward trend could be established. However, because of the very low dose and associated uncertainty, this evaluation was truncated at a final annealing temperature of $470{ }^{\circ} \mathrm{C}$.)

\subsubsection{SiC Monitor Evaluation Summary}

SiC monitors, identified as KGT-1174, KGT-1208, and KGT-1139, were evaluated in an attempt to infer peak irradiation temperatures during the ATR NSUF University of Illinois Project 29609 irradiation. The peak irradiation temperatures inferred from the resistivity measurements of those SiC monitors are summarized in Table 4. As indicated, it was not possible to infer peak irradiation temperatures for the KGT-1174, KGT-1208, or KGT-1139 monitors. This is attributed to the fact that their exposure was below the recommended minimum value for using such monitors. 


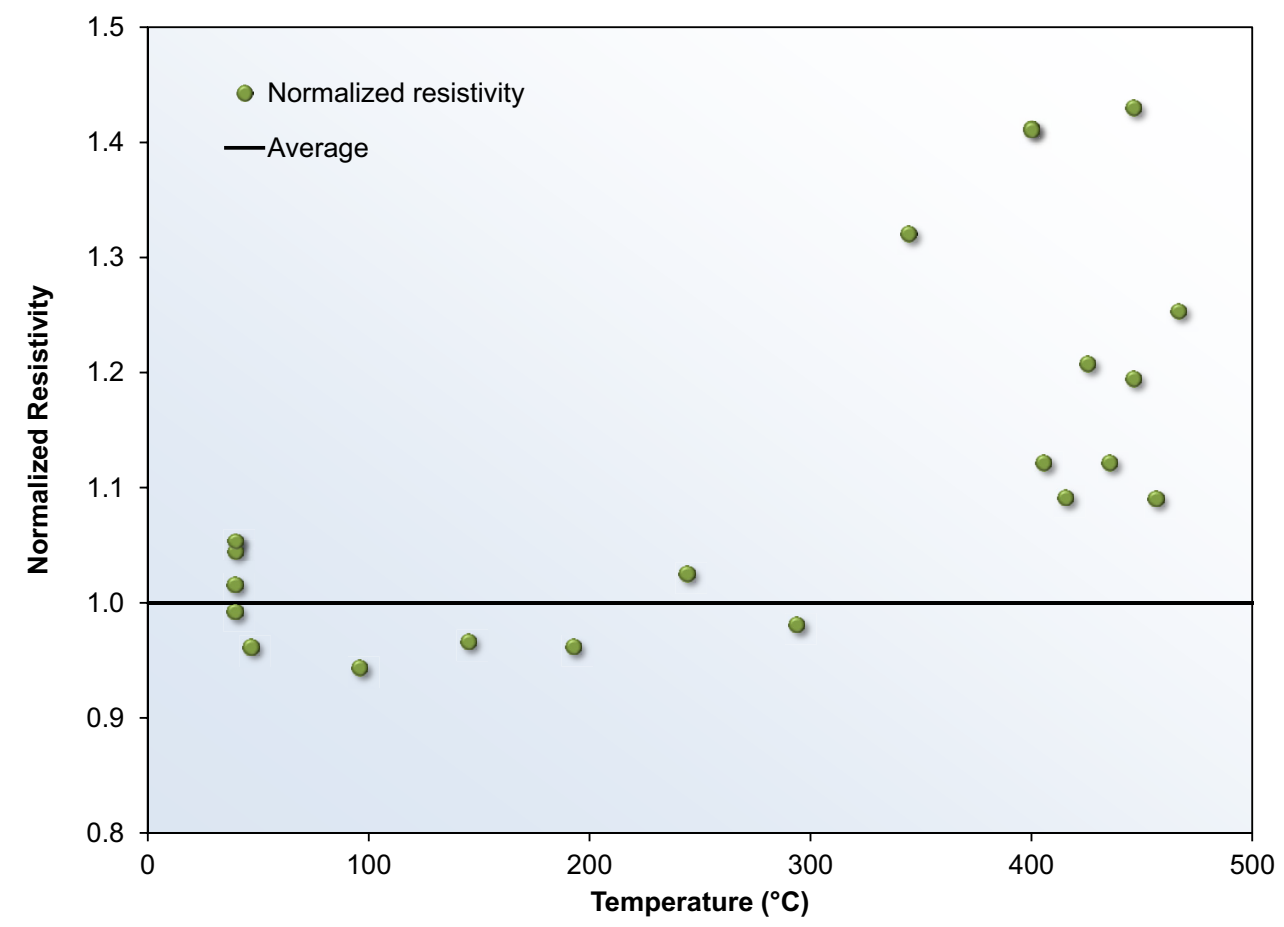

Figure 14. Resistivity data for KGT-1139 monitor.

Table 4. Summary of SiC evaluation results.

\begin{tabular}{|c|c|c|c|}
\hline Monitor & $\begin{array}{c}\text { Inferred Peak } \\
\text { Temperature }\left({ }^{\circ} \mathrm{C}\right)\end{array}$ & Dose $(\mathrm{dpa})$ & $\begin{array}{c}\text { Predicted Test } \\
\text { Temperature }\left({ }^{\circ} \mathrm{C}\right)\end{array}$ \\
\hline KGT-1174 & Indeterminate & $<<0.01$ & 300 \\
\hline KGT-1208 & Indeterminate & 0.01 & 450 \\
\hline KGT-1139 & Indeterminate & 0.1 & 450 \\
\hline
\end{tabular}

\section{Conclusions}

SiC monitors were used in selected positions during the ATR NSUF University of Illinois Project 29609 irradiation as a way to determine peak irradiation temperatures reached during the test. Three of the SiC monitors that were used were evaluated to infer those temperatures. However, post-irradiation annealing techniques could not be used to infer a peak irradiation temperature for any of these monitors. A primary factor contributing to this problem is believed to be the fact that the $\mathrm{SiC}$ monitors were used outside the recommended dose ranges. Based on these results, it therefore appears that $\mathrm{SiC}$ monitors cannot be reliably used outside of recommended ranges.

\section{References}

1. J. Gan, "Project 29609- Irradiation Test Plan for the ATR NAtional Scientific User Facility - University of Illinois Project," PLN-2998, October 4, 2010.

2. W. F. Jones, “Thermal Analysis - ATR NSUF University of Illinois HSIS Experiment," ECAR-1293, March 18-2011. 
3. J. R. Mitchell, "ATR Neutronics Evaluation for the University of Illinois Experiment in the HSIS," Project 29609, ECAR-1327, June 2, 2011.

4. D. L. Knudson, "Melt Temperatures for the Zr Growth Experiment Melt Wires," TEV-1007, September 2010.

5. K. L. Davis and D. L. Knudson, "Specimen Melt Temperatures for Use in the Advanced Test Reactor," TEV-1175, March 2011.

6. K.L. Davis, “Melt Wire Testing,” INL Interoffice Memorandum, October 14, 2011.

7. K. L. Davis, D.L. Knudson, J.E. Daw, J.L.Rempe and A.J. Palmer, "Melt Wire Sensors Available to Determine Peak Temperatures in ATR Irradiation Testing," 8th International Topical Meeting on Nuclear Plant Instrumentation, Control, and Human Machine Interface Technologies (NPIC\&HMIT 2012), San Diego, CA, July 22-26, 2012.

8. J. L. Rempe, K.G. Condie, Darrell Knudson, and L. L. Snead, Silicon Carbide Temperature Monitor Measurements at the High Temperature Test Laboratory, INL/EXT-10-17608, January 2010.

9. P. E. Murray, "Thermal Analysis of Irradiation Experiments in the ATR", Test Research and Training Reactors (TRTR) Annual Meeting, San Diego, CA, September 2012

10. L. L. Snead, A. M. Williams, A. L. Qualls, "Revisiting the use of SiC as a Post Irradiation Temperature Monitor", Effects of Radiation on Materials, ASTM STP 1447, M. L. Grossbeck, Ed, ASTM International, West Conshohocken, PA, 2003. 